\title{
SMS reminders to improve adherence and cure of tuberculosis patients in Cameroon (TB-SMS Cameroon): a randomised controlled trial
}

\author{
Georges Bediang $^{1 *}\left(\mathbb{D}\right.$, Beat Stoll², Nadia Elia², Jean-Louis Abena ${ }^{3}$ and Antoine Geissbuhler ${ }^{4}$
}

\begin{abstract}
Background: In Cameroon, the National Tuberculosis Control Program that applies selective directly observed treatments faces difficulties in its implementation for a lack of resources, leading to only $65 \%$ of patients with sputum smear-positive pulmonary tuberculosis being cured after 6 months of treatment. This study aimed to evaluate the effectiveness of daily Short Message Service reminders to increase adherence and the proportion of adult tuberculosis patients cured after 6 months of treatment.
\end{abstract}

Methods: A simple blinded, randomised controlled, multicentre study carried out in 12 Treatment and Diagnostic Centres of Yaoundé. The patients included were randomly assigned to two groups: patients in the intervention group received daily SMS reminders in addition to the usual treatment; those in the control group received the usual treatment only. The primary outcomes were the number and proportion of treatment success at 5 months, and the number and proportion of patients cured at 6 months. Data analysis was by intention to treat.

Results: Two hundred and seventy-nine participants were randomized into intervention group $(n=137)$ and control group $(n=142)$. At five months, there were 111 treatment success (81\%) in the intervention group and 106 $(74.6 \%)$ in the control group $(\mathrm{OR}=1.45[0.81,2.56] ; p=0.203)$. At 6 months, there were 87 patients cured $(63.5 \%)$ in the intervention group and $88(62 \%)$ in the control group $(\mathrm{OR}=1.06[0.65,1.73] ; p=0.791)$. The number of dropouts at 6 months was 47 (34.3\%) in intervention group, and 46 (32.4\%) in the control group. 48.9\% (23/47) and 39. $1 \%(18 / 46)$ of these drop-outs were sputum-negative at 5 months. At three different appointments, there were no significant differences between the two groups in any secondary outcomes. Very high and similar satisfaction was found for general management of patients in both groups: 99.5 and $99.2 \%(p=0.41)$.

Conclusions: Our study suggests that SMS reminders do not increase treatment success and cure proportions. However, the low proportion of patients cured at 6 month may be an underestimation due to a high dropout rate between the fifth and the sixth months of treatment. Future trials should focus on reducing the dropout rate.

Trial registration: The trial was registered on the Pan-African Clinical Trials Registry (PACTR201307000583416 of 22 July 2013) and the protocol was published.

Keywords: SMS-reminders, Text messaging, mHealth, Effectiveness, Tuberculosis, Developing countries, Low-middle income countries, Africa

\footnotetext{
* Correspondence: bediang@yahoo.com

${ }^{1}$ Faculty of Medicine and Biomedical Sciences, University of Yaoundé I, P.O

Box: 1364, Yaoundé, Cameroon

Full list of author information is available at the end of the article
}

(c) The Author(s). 2018 Open Access This article is distributed under the terms of the Creative Commons Attribution 4.0 International License (http://creativecommons.org/licenses/by/4.0/), which permits unrestricted use, distribution, and reproduction in any medium, provided you give appropriate credit to the original author(s) and the source, provide a link to the Creative Commons license, and indicate if changes were made. The Creative Commons Public Domain Dedication waiver (http://creativecommons.org/publicdomain/zero/1.0/) applies to the data made available in this article, unless otherwise stated. 


\section{Background}

Tuberculosis (TB) is one of the major public health problems in developing countries $[1,2]$. In Cameroon, the prevalence of tuberculosis (all forms included) is of 122 per 100,000 inhabitants. In 2010, 24,528 cases (all forms included) were recorded. The number of new cases of sputum Koch smear positive pulmonary tuberculosis was 14,464 [3]. The proportion of co-infection with HIV was estimated at 33\% [3].

To address TB problem around the world, the international community led by the World Health Organisation (WHO) and its partners, developed international strategies and guidelines to fight against TB: Directly Observed Treatment Short Course (DOTS [4]), Global Strategy and Plan to Stop TB $([5,6])$ and now, WHO End TB Strategy [7].

The DOTS strategy was designed to improve the management of TB patients in order to increase their adherence to the full treatment of 6 months, and the proportion of cured patients. Failure to comply with the 6 months leads to high risk for relapse and increases overall resistance against the anti-TB drugs. This strategy includes a sustained political commitment; access to quality-assured TB sputum microscopy; standardized short-course chemotherapy to all cases of $\mathrm{TB}$ under proper case-management conditions including direct observation of treatment (DOT); uninterrupted supply of quality-assured drugs; and recording and reporting system enabling outcome assessment [8].

Because of numerous infrastructural, organizational, economic, and logistic limits in developing countries [9-11], the overall DOTS strategy is not correctly implemented and adaptations were developed. For example, direct observation of patient taking the medication by a healthcare worker during the intensive treatment phase is rarely correctly implemented. All these limiting factors lead to a reduction of the effectiveness of the program, namely poor adherence of patients to treatment and its consequences such as low cure proportion, relapse, or drug resistance. [12-16]

In Cameroon, the DOTS strategy is implemented by the National Program for the fight against tuberculosis (PNLT) [3] financed by the Government of Cameroon in collaboration with international funding partners such as The Global Fund to Fight AIDS, Tuberculosis and Malaria. Instead of receiving daily directly observed drug intake during the first 2 months of treatment, the patient receives several doses on a weekly or monthly basis. In 2010 , only around $77 \%$ of sputum smear-positive pulmonary tuberculosis $(\mathrm{SS}+\mathrm{PTB})$ patients completed their 6 months treatment, with confirmed sputum smear negativity at 5 months and 65\% were considered "cured" (patients who completed 6 months treatment with a sputum smear-negative result at 6 months) [17]. This proportion of cure is $20 \%$ below the WHO objective [8]. The main cause of low cure proportion in Cameroon is non-adherence to treatment of patients [3]. This could be due to lack of communication and interactions between healthcare professionals and patients through the care process.

Based on the progressive dissemination of mobile health technology (mHealth) and its feasibility, acceptability and ability to enhance patient motivation [18-23] in developing countries - and considering particularly its potential to improve TB treatment adherence and care [24-30] - we carried out a SMS-based intervention. The protocol of this trial was published [31] and registered (PACTR201307000583416).

\section{Methods}

More details on the methodology of this study have been published [31]. There were no significant changes to the initial protocol. The findings of this study are reported according to CONSORT (Consolidated Standards of Reporting Trials) 2010 statement [32].

\section{Objectives}

The primary objective was to evaluate the effectiveness of daily SMS reminders to increase the proportion of cure of adult patients who were newly diagnosed with sputum positive pulmonary tuberculosis $(\mathrm{SS}+\mathrm{PTB})$ and followed in Treatment and Diagnostic Centres (TDC) in Yaoundé, Cameroon. We formulated the hypothesis that sending daily SMS to remind patients to take their prescribed anti-tuberculosis medication - on top of selective DOT (once weekly or monthly distribution of drug) - would increases the proportion of patients cured from $65 \%$ (DOT, no SMS intervention) to $85 \%$ (DOT, with SMS intervention).

The secondary objective was to evaluate the effectiveness of sending SMS reminders on: patients' selfestimation of adherence to anti-tuberculosis treatment; the attendance to appointments; the punctuality to appointment dates, and the degree of patients' satisfaction at 6 months.

\section{Trial design}

This was a randomised, single blinded (for healthcare professionals delivering the drugs and assessing sputumsmears), controlled and multicentre trial. Patients were randomly allocated to one of two groups in each centre (ratio 1:1): an intervention group in which participants received daily SMS reminders in addition to the usual treatment and a control group where participants did not receive reminders. 


\section{Participants and setting}

Patients were recruited in Treatment and Diagnostic Centres (TDCs) of Yaoundé between February and October 2013, and followed until April 2014. The city of Yaoundé has seventeen (17) TDCs, of which sixteen (16) were eligible, as the TDC located in Yaoundé prison was excluded (prisoners are not allowed to have phones).

Eligible patients had to be adults ( $>18$ years), newly diagnosed SS + PTB (clinical signs of pulmonary tuberculosis with two microscopic sputum smear examinations, one of which at least had to be positive), be able to read French or English, and in possession of a mobile phone for personal use. In addition, they had to know how to open and read an SMS on their telephone and to have given written consent to study participation after having been informed about it. After recruitment, all participants received a welcome SMS, followed by a phone call from the research team in order to check whether the phone number really belonged to the patient. This last step determined the definitive inclusion of the patient into the study.

\section{Interventions}

All participants received the usual care (selective DOT) from the PNLT. This includes: free anti-tuberculosis treatment with an intensive phase (four-drug therapy for the first 2 months made of rifampicin, isoniazid, ethambutol and pyrazinamide) followed by a continuation phase (bi-therapy from the third to the sixth month made of rifampicin and isoniazid), appointments for drug refills (weekly for the first 2 months and monthly between the third and sixth months), three smear control tests at the end of the second, fifth and sixth months, and education coupled with counselling of patients throughout the process.

Patients in the intervention group received, in addition, free and daily SMS reminders in French (French being one of national languages, and all of them were French-speaking) throughout the 6 months of treatment. In the intervention group, the phone call made after the welcome SMS was not only to guarantee that the phone belonged to the patient but also that the latter had read the content of the welcome SMS. The SMS content was designed during a workshop by the research team. The purpose was to deliver simple and easy SMS aiming at reminding, inciting or motivating the patients to take the prescribed anti-tuberculosis medications. To maintain the patients' attention and interest, these messages changed every 2 weeks. Here is the batch of SMS sent during the first 2 months of treatment as an illustration of this:

(i) "Hello, please don't forget to take your TB treatment"; (ii) "Hello, it's important to take your TB drugs every day", (iii) "Hello, taking TB drugs daily increases your chance of healing", (iv) "Hello, thank you for continuing to take TB treatment", etc.). Additional encouraging messages were also sent every 2 weeks (e.g.: (i) "Congratulation, the second week of treatment is over!", (ii) "Congratulation, the first month of treatment is over!", (iii) "Congratulation, the sixth week of treatment is over!", (iv) "Congratulation, the second month of treatment is over!", etc.). Messages were neutral, similar for both genders. Patients also received a message at the end of treatment to thank them for participating in the study.

At each visit, health professionals verified (by asking to patient) that patients still had same telephone contacts they provided when they were included in the study. Patients in the control group only received a welcome SMS at the beginning, the phone call after the welcome SMS, and a SMS at the end of the 6 months treatment period to thank them for their participation. As such, they did not receive daily SMS reminders.

\section{Outcomes}

The primary outcome was the proportion of patients cured. These were defined as such when having completed the 6 months treatment with bacteriologic confirmation of conversion to sputum smear-negative at 6 months. We also associated as primary outcome the proportion of patient with "treatment success", defined as having completed the 6 months treatment and having negative sputum smears at 5 months.

The secondary outcomes were: (i) patients' selfestimation of adherence to treatment on a 0 to $100 \%$ scale during the last 30 days before appointments, (ii) proportion of patient attending appointments (whether the patient was present or not), (iii) the punctuality to appointment dates ("early" for participants coming more than four days before the appointment date, "prompt" for participants coming between four days before and four days after the appointment date and "late" for participants coming more than four days after the appointment date). They were evaluated during follow-up visits at two, five, and six months. Finally (iv), we evaluated the degree of patients' satisfaction at the end of the sixth month using Likert Scale.

During the study, patients had six mutually exclusive possible treatment outcomes: "cured" (sputum smearnegative at 6 months of treatment); "treatment success" (sputum smear-negative at 5 months of treatment but no final smear result at 6 months); "treatment failure" (sputum smear-positive at five or 6 months of treatment); "transferred" (patient referred in another TDC out of the study zone in order to continue treatment 
without feedback from the receiving TDC; "died" (patient died between the screening phase and the end of treatment, no matter the cause of death) and "loss to follow-up".

\section{Sample size}

The sample size calculation was based on an estimation of the baseline proportion of patients "cured" with DOTS strategy in Cameroon of 65\% [17]. Our hypothesis was that the proportion of patients cured in the intervention group would increase to $85 \%$. Thus, this study was designed to detect a $20 \%$ increase of cures, with $80 \%$ of power, $5 \%$ of alpha error and " two-sided " tests. Using online Open Epi software [33], the required sample size was 166 participants. Considering the risks of loss-to-follow-up and of missing data we increased the sample size to 260 eligible patients.

\section{Randomisation, allocation and blinding}

Based on the activity of TDC (data obtained from PNLT), we calculated the proportion of patients to be recruited in each TDC (e.g. The Jamot Hospital which is the biggest TDC of Yaoundé was expected to contribute about $55 \%$ of the sample). Eligible and consenting patients attached to each centre received numerical codes (e.g. A001, A002, etc. for centre A). This code was assigned consecutively over the recruitment of patients, who were also stratified by recruitment centres (use of random block sizes), and randomised into the two groups (intervention and control groups) with an allocation ratio of 1:1. Randomisation was carried out by research team using a computer generated list. This allocation list was kept by the research team and concealed to healthcare professionals. Once a patient was recruited by a healthcare professional, the study identifiers and telephone numbers were communicated to the research assistant who allocated him/her in one of the two groups according to the randomisation scheme. Thus, healthcare professionals were blinded to randomisation and allocation of patients into two groups during the recruitment phase, thereby preventing allocation or selection biases.

\section{Data collection and supervision}

Data on patients were collected by healthcare professionals taking care of them using patient follow-up forms elaborated by the research team (which contained all the necessary questionnaires, scales, etc.) and kept in the patients' health records. These forms were updated during each visit (day of inclusion, second, fifth, and sixth months). An information and training session organized before the start of the study allowed training healthcare professionals in the correct completion of the forms.
A research assistant collected telephone numbers during the recruitment phase from the patient forms once a week at each TDC in order to continuously provide and update the phone numbers database with relevant phone numbers of newly enrolled patients. At the end of the 6th month, healthcare professionals administered a selfevaluation questionnaire to evaluate patient satisfaction.

Two sessions of supervision of research activities were carried out at the end of third and at eighth month after recruitment. The first session aimed to evaluate the recruitment of patients in each TDC, the completion of the consent form, the sending of SMS reminders as well as the checking of their reception by patients, and the quality of collected data in all TDC by healthcare professionals. The second session aimed to evaluate the follow-up of patients in the 12 recruiting TDC according to research protocol and the quality of collected data. This supervision was made by an evaluator from the research team. At the end of each supervision activity, recommendations were made by the evaluator in order to correct observed discrepancies between the protocol and the findings on the ground.

\section{Statistical analysis}

A data entry form was developed with the Epi Data Entry software (version 3.1, available freely at http:// www.epidata.dk/) was used to enter participants' data and to carry out double data entry and validation. Outcomes (primary and secondary) were analysed on an «Intention to Treat » (ITT) basis. For primary outcomes, all patients lacking information on their smear test at 5 or 6 months were considered as not cured (worst case scenario).

Results of this study are presented as mean (standard deviation) and median (inter-quartile ranges) for continuous variables depending on their underlying distribution, and frequencies (percentages) for categorical variables. The two groups are described according to their baseline characteristics and primary and secondary outcomes at 2, 5, and 6 months. Differences between the two groups were tested using Student (T-test) and Mann-Whitney tests for continuous variables according to the underlying variable distribution; Chi-square and Fisher's exact tests for categorical or nominal variables. The comparisons are reported as odds ratios (OR) with 95\% confidence intervals (CI).

\section{Additional analyses}

A logistic regression model was built to identify sociodemographic factors (age, gender, level of education, socioeconomic category, marital status, incomes and HIV status) that could help to predict which patients were likely to be lost-to follow-up during their treatment. Data from 
this study were analysed using SPSS programme (v22.0) and Online Open Epi Software [33].

\section{Material and equipment for sending SMS}

A web proprietary platform [34] has been used to send daily SMS messages to participants. This application can $\log$ SMS messages and allows to produce reports of those sent. The platform was tested before using it for the intervention to ensure its effectiveness (failure rate), especially in sending grouped SMS. This system proved to be effective and satisfactory.

\section{Results}

\section{Recruitment and patient flow}

Patients were recruited in 12 of the 16 eligible TDCs of Yaoundé city only. Two hundred eighty-two (282) potentially eligible patients were contacted between February and October 2013 for their recruitment in the study, of whom three declined to participate. Two hundred seventy-nine (279) patients were thus randomly allocated to two groups (137 to the intervention group and 142 to the control group) and were followed during 6 months.

At 2 months, 125 (91.2\%) patients in intervention and $124(87.3 \%)$ in the control groups were still followed $(\mathrm{OR}=1.51[0.69,3.27] ; p=0.29)$. At 5 months, they were $112(81.7 \%)$ and $108(76.0 \%)$ respectively $(\mathrm{OR}=1.41[0$. $78,2.51] ; p=0.24)$. Finally at 6 months, they were 88 $(64.2 \%)$ and $90(63.4 \%)$ respectively $(\mathrm{OR}=1.03[0.63,1$. 69]; $p=0.88)$.

Approximately half $(n=24)$ of patients withdrew in the intervention group between the fifth and the sixth month, while in the control group, about one-third ( $n=$ 18) of patients withdrew at each appointment. Figure 1 shows the flow diagram of patients throughout the study.

\section{Baseline data}

Data from 279 randomized participants were analysed. There is a homogeneous distribution of participants in both groups (Table 1), except for the prevalence of TB HIV co-infection: about $20 \%$ of patients were HIV positive in the intervention group, less than $10 \%$ in the control group $(p=0.02)$.

\section{Outcomes and estimation \\ Primary outcomes}

At the 5th month, the treatment success (Table 2) was $81 \%(n=111)$ in the intervention group and $74.6 \%(n=$ $106)$ in the control group (OR $=1.45[0.81,2.56] ; p=0.20)$. About $1.5 \%(n=2)$ of the patients had a treatment failure (patients with still sputum smear-positive at 5 months) in each group. One of the two sputum smear-positive patients in the intervention group was transferred between the second and fifth month.

At month six, the proportion of patients cured (Table 2) was $63.5 \%(n=87)$ in the intervention group and $62 \%$ $(n=88)$ in the control group $(\mathrm{OR}=1.06[0.65,1.73] ; p=$ $0.79)$. One patient in the intervention group and two in the control group were still sputum smear-positive at six months.

\section{Secondary outcomes}

There were no significant differences between the two groups in any secondary outcomes as shown in Table 3. It should be noted that strong adherence to treatment during the last 30 days of the three appointments - as described by patients using visual analogue scale - was observed in both groups.

Finally, we found a very high level of and similar satisfaction in both groups, regarding (i) general management of patients $(99.5 \%$ of satisfaction in the intervention and $99.2 \%$ in the control group (MD: 0.3\% $[-0.4,1.0 \%] ; p=0.41$ ) and (ii) support provided for adherence to drug prescriptions $(99.6 \%$ of satisfaction in the intervention group and $99.1 \%$ in the control group (MD: $0.5 \%[-0.2,1.2] ; p=0.17$ ).

\section{Additional analyses}

Furthermore, our study confirms that patients who are retained during the 6 months in DOT such as practiced currently - both in intervention and control groups respectively - have a very high cure proportion at 6 months, if the number of patients with smear-negative is divided by the number of patients present at the last appointment for each group (per protocol analysis): 98.9 and $97.8 \%(\mathrm{OR}=1.97[0.17,22.2] ; p=0.73)$.

As we observed a high rate of withdrawn patients throughout the study (lost to follow-up or transferred participants for whom no information about outcome is available) and especially before the appointment of six months $(34.3 \% ; n=47$ in the intervention group and 32 . $4 \% ; n=46$ in the control group), we examined and compared the sociodemographic profile of these withdrawn patients among the 2 groups (Table 4). Apart from HIV status (as observed in the baseline), there was no significant difference between both groups. In addition, we also examined and compared the sociodemographic profile of these withdrawn patients with the patients that remained in the trial throughout (Table 5). The binary logistic regression test performed was unable to identify any sociodemographic characteristics predicting lost-tofollow-up.

\section{Limitations}

Only 12 of the 16 TDC of Yaoundé participated in this study. Two elements can explain the non-recruitment of 


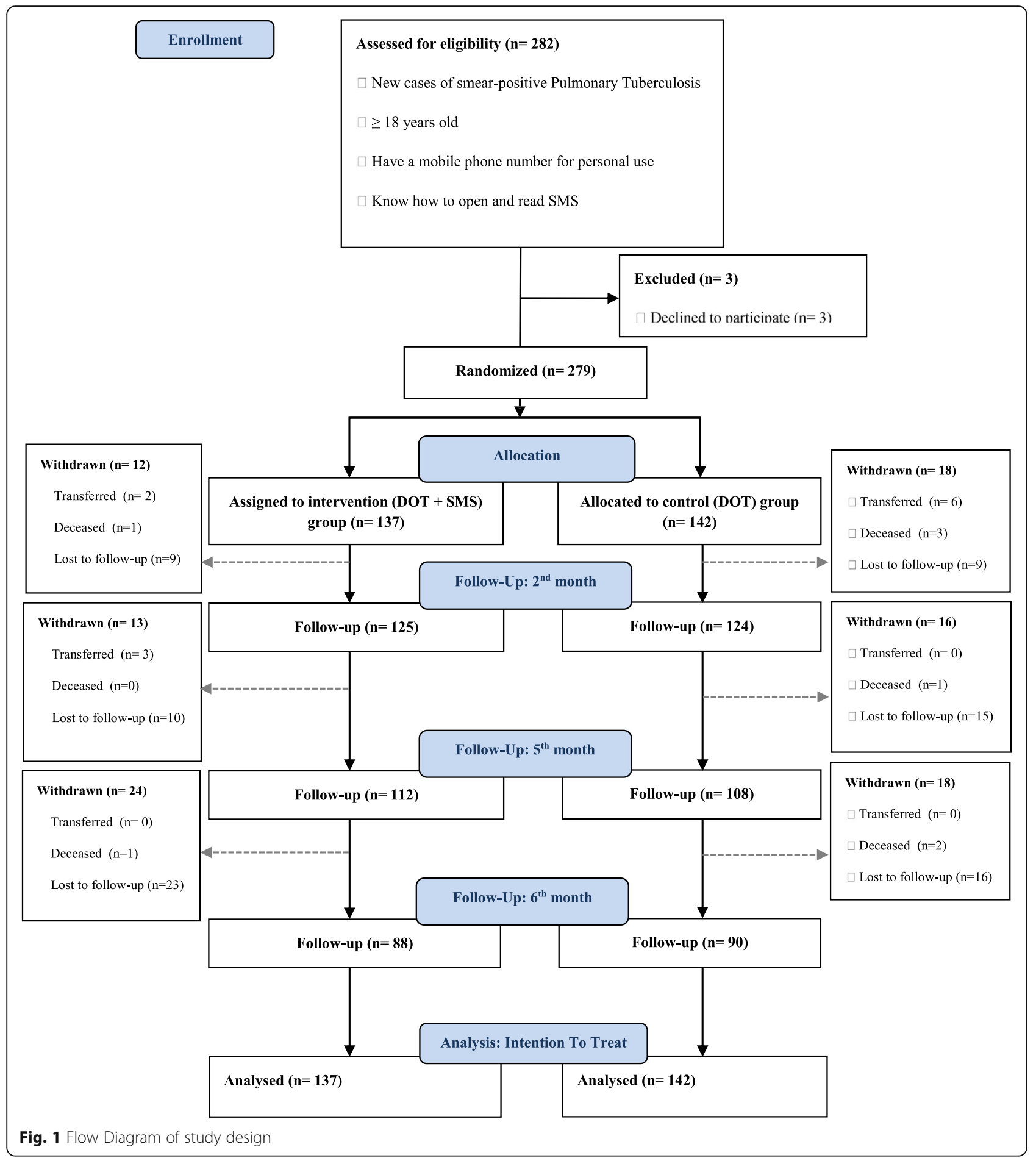

patients in these TDCs: the refusal of some health professionals to participate in the study and staff rotations that occurred just after the beginning of the study.

In addition, some TDCs have not achieved the quotas of recruitment that were set for them quickly enough.
Thereby, this led the extension of the time needed to recruit patients (10 months instead of 4 months as initially planned).

Another problem concerned the collection of some data in TDC (namely participants' phone numbers) in order to constantly update the SMS distribution list. The 
Table 1 Demographics and baseline characteristics of participants in both groups

\begin{tabular}{|c|c|c|}
\hline Variables & $\begin{array}{l}\text { Intervention group } \\
(\mathrm{DOT}+\mathrm{SMS}) n=137\end{array}$ & $\begin{array}{l}\text { Control group } \\
\text { (DOT) } n=142 \\
\end{array}$ \\
\hline \multicolumn{3}{|l|}{ Gender: n (\%) } \\
\hline Male & $86(62.8)$ & 79 (55.6) \\
\hline Female & $51(37.2)$ & $63(44.4)$ \\
\hline \multicolumn{3}{|l|}{ Age (years): n (\%) } \\
\hline $18-25$ & $22(16.1)$ & $34(23.9)$ \\
\hline $26-40$ & $84(61.3)$ & $79(55,7)$ \\
\hline $41-55$ & $26(18.9)$ & $20(14,1)$ \\
\hline $56-80$ & $5(3.7)$ & $9(6,3)$ \\
\hline \multicolumn{3}{|l|}{ Level of Education: n (\%) } \\
\hline None & $7(5.2)$ & $4(2.9)$ \\
\hline Nusery/primary & $38(27.9)$ & $34(23.9)$ \\
\hline Secondary & $69(50.1)$ & $74(52.1$ \\
\hline Tertiary & $23(16.8)$ & $30(21.1)$ \\
\hline \multicolumn{3}{|l|}{ Marital Status: n (\%) } \\
\hline Single & $84(61.3)$ & $93(65.5)$ \\
\hline Married & $40(29.1)$ & $37(26.0)$ \\
\hline Cohabitation & $11(8.0)$ & $7(5.0)$ \\
\hline Widower & $1(0.8)$ & $5(3.5)$ \\
\hline Divorced & $1(0.8)$ & $0(0.0)$ \\
\hline \multicolumn{3}{|l|}{ Social Category: n (\%) } \\
\hline Student & $21(15.3)$ & $25(17.6)$ \\
\hline Working in public sector & $7(5.1)$ & $14(9.8)$ \\
\hline Working in formal private sector & $20(14.6)$ & 15 (10.6) \\
\hline Working in informal private sector & $41(30.0)$ & $37(26.0)$ \\
\hline No work & $48(35.0)$ & $51(36.0)$ \\
\hline \multicolumn{3}{|l|}{ Monthly Income (XAF): n (\%) } \\
\hline$<50,000$ & $40(29.2)$ & $31(21.8)$ \\
\hline $50,000-149,000$ & $20(14.6)$ & $25(17.6)$ \\
\hline$>149,000$ & $5(3.7)$ & $3(2.1)$ \\
\hline Not reported (missing) & $72(52.5)$ & $83(58.5)$ \\
\hline \multicolumn{3}{|l|}{ HIV Status: n (\%) } \\
\hline Negative & $85(62.0)$ & $98(69.0)$ \\
\hline Positive & $27(19.7)$ & $12(8.5)$ \\
\hline Unknown & $25(18.3)$ & $32(22.5)$ \\
\hline Patient on ART (yes): n (\%) & $10(7.3)$ & $7(4.9)$ \\
\hline Microscopy (positive): n (\%) & $137(100)$ & $142(100)$ \\
\hline Treatment plan (2RHEZ/4RH): n (\%) & $137(100)$ & $142(100)$ \\
\hline $\begin{array}{l}\text { Duration of treatment (months): } \\
\text { Mean (SD) / Median (Q1-Q3) }\end{array}$ & $\begin{array}{l}6.6(1.2) / \\
6.2(6.0-6.7)\end{array}$ & $\begin{array}{l}6.5(1.3) / \\
6.1(6.0-6.6)\end{array}$ \\
\hline
\end{tabular}

DOT directly observed treatment, SMS short message service, 1 US Dollar 599 XAF (F CFA, currency used in Cameroon), HIV human immunodeficiency virus, ART anti-retroviral therapy, 2RHEZ/4RH 2 months of rifampicin, isoniazid, ethambutol, pyrazinamide and 4 months of rifampicin and isoniazid, $S D$ standard deviation, Q1 first quartile, Q3 third quartile

initial planned collection frequency was twice a week during the recruitment phase, but for logistical reasons it was reduced to once a week.
As illustrated in the flow diagram of patients, we observed a significant number of total withdrawn patients (lost to follow-up, transferred and deceased) throughout 
Table 2 Primary outcomes

\begin{tabular}{llll}
\hline Primary outcomes & $\begin{array}{l}\text { Intervention group } \\
(\mathrm{DOT}+\mathrm{SMS}) n=137 \\
\mathrm{n}(\%)\end{array}$ & $\begin{array}{l}\text { Control group } \\
(\mathrm{DOT}) n=142 \\
\mathrm{n}(\%)\end{array}$ & $\begin{array}{c}\text { Effect Estimate } \\
\text { OR [95\% Cl]; } p\end{array}$ \\
\hline $\begin{array}{l}\text { Megroscopy at } 5 \text { months } \\
\text { Microscopy at } 6 \text { months }\end{array}$ & $111(81.0)$ & $106(74.6)$ & $1.45[0.81,2.56] ; 0.20$ \\
$\quad$ & & $88(62)$ & $1.06[0.65,1.73) ; 0.79$ \\
\hline
\end{tabular}

DOT directly observed treatment, SMS short message service, OR odds ratio, $\mathrm{Cl}$ confidence interval

the study. At the appointment of 6 months, the total of withdrawn patients was $35.8 \%(n=49)$ in the intervention group and $36.6 \%(n=52)$ in the control group (OR $=0.96[0.59-1.57] ; p=0.88)$.

Finally, it appeared impossible to assess drug resistance to patients with failure at 5 months of treatment with the GeneXpert [35] as announced in the research protocol. The functional capabilities of PNLT at the time of the study did not allow to carry out this exam systematically. The contacts of these four participants affected were given to the national program coordinator to take them in charge outside of the study.

\section{Discussion}

This study explores the potential of a m-health intervention to improve the proportion of pulmonary tuberculosis patients cured in Cameroon. The cure rate was of $65 \%$ of the treated patients at the beginning of the study, and we expected to improve it to $85 \%$, corresponding to the WHO recommendations [36]. Many national programs have introduced weekly or monthly observed treatment strategies, which do no longer correspond to original DOT which recommend to healthcare professionals a daily follow-up of patients for drug intake, especially in the intensive phase. In this context, sending daily SMS reminders requires less resources as daily DOT, but also less time, staff, organization, and funding $[37,38]$ and prevents stigmatization of patients.

Unfortunately, the results obtained in this study suggest that the proportion of patients cured at 6 months is almost similar in both groups (around 63\%) and below the $85 \%$ expected.

Several reasons explain our results. Firstly, we used an intention to treat analysis, which considers as "treatment failure" any patient missing the final appointment, without giving precise information to explain his/her absence. This contributes to the very low proportion of the patients cured. Most of patients who dropped-out - or were transferred - did so between the 5th and 6th month. We may presume that many of them were in fact cured, felt well, and were not willing to pay out of their pocket for the last required sputum exam for not being part of the free treatment package offered by the national
TB control program. Secondly, one of the main public health objectives in the management of SS + PTB patients is to reduce transmission throughout the population. As such, international guidelines require at least 6 months treatment regimens even if it is known that patients who had TB once are at higher risk of reinfection than subjects who never experienced TB-disease in their life before [39]. Is this risk really higher for newly diagnosed SS + PTB patients who fulfilled the TB treatment protocol -2 months of a quadritherapy with Rifampicin, Isoniazid, Ethambutol, and Pyrazinamide followed by 4 months of bi-therapy with Rifampicin and Isoniazid - and proved smear-negative sputum after 5 months? Unfortunately we did not find conclusive statements in the medical literature.

The results obtained at 5 months, showed that the proportion of patients with treatment success is higher (approximately 6\% difference) in the intervention group compared to the control group (81\% versus $74.6 \%$, OR = $1.45[0.81,2.56] ; p=0.20)$. Although not statistically significant, it suggests a trend in favour of SMS reminders, with cure rates approaching what is expected from WHO. This is consistent with a study carried out in the Republic of South Africa which found a treatment success of $72.94 \%$ in the SMS group compared to $69.4 \%$ in the DOT group [27].

The use of mHealth in general - and SMS for the management of $\mathrm{TB}$ - has been described in many studies [24-30]. For improving TB treatment adherence and cure proportion, a systematic review conducted in 2013 noted the lack of sufficient evidence on the effectiveness of SMS [29]. In our study, despite acceptability and positive perception of patients about SMS reminders [22], the relative weak added effect of SMS to support treatment adherence and to improve cure and treatment success rates of $\mathrm{SS}+\mathrm{PTB}$ patients at 5 and 6 months respectively, led us to ask questions about the relevance and challenges of such intervention in low and middle income countries like Cameroon. Should SMS reminders be formatted differently in order to contribute to better treatment adherence? If more patients are retained in DOT, then more of them will have their cured status confirmed and resistant cases will be prevented ultimately [37]. 
Table 3 Secondary outcomes

\begin{tabular}{|c|c|c|c|}
\hline \multirow[t]{2}{*}{ Secondary outcomes } & $\begin{array}{l}\text { Intervention group } \\
(\mathrm{DOT}+\mathrm{SMS}) \mathrm{n}=137\end{array}$ & $\begin{array}{l}\text { Control group } \\
(\mathrm{DOT}) \mathrm{n}=142\end{array}$ & Effect Estimate \\
\hline & $\mathrm{n}(\%)$ & $\mathrm{n}(\%)$ & OR $[95 \% C I] ; p$ \\
\hline \multicolumn{4}{|l|}{ At 2 months } \\
\hline \multicolumn{4}{|l|}{ Attendance to appointments } \\
\hline Number of patients followed & $125(91.2)$ & $124(87.3)$ & $1.51[0.69,3.27] ; 0.29$ \\
\hline Number of patients withdrawn & $12(8.7)$ & $18(12.7)$ & $0.66[0.30,1.43] ; 0.29$ \\
\hline Transferred out & $2(1.5)$ & $6(4.2)$ & $0.33[0.06,1.69] ; 0.16$ \\
\hline Deceased & $1(0.7)$ & $3(2.1)$ & $0.34[0.03,3.31] ; 0.33$ \\
\hline Lost to follow-up & $9(6.6)$ & $9(6.4)$ & $1.03[0.39,2.70] ; 0.93$ \\
\hline \multicolumn{4}{|l|}{ Punctuality to appointment dates } \\
\hline Early and Prompt & $98(71.5)$ & $104(73.2)$ & $0.91[0.54,1.55] ; 0.74$ \\
\hline \multirow[t]{2}{*}{ Late } & $27(19.7)$ & $21(14.8)$ & $1.41[0.75,2.64] ; 0.27$ \\
\hline & $\begin{array}{l}\text { Mean (SD) / } \\
\text { (Min, Max) }\end{array}$ & $\begin{array}{l}\text { Mean (SD) / } \\
\text { (Min, Max) }\end{array}$ & $\operatorname{MD}[95 \% \mathrm{Cl}] ; p$ \\
\hline Adherence to prescription drugs (\%, VAS) & $\begin{array}{l}98.5(6.3) / \\
(50,100)\end{array}$ & $\begin{array}{l}99.3(3.5) / \\
(70,100)\end{array}$ & $-0.8[-2.0,0.5] ; 0.25$ \\
\hline \multicolumn{4}{|l|}{ At 5 months } \\
\hline \multicolumn{4}{|l|}{ Attendance to appointments } \\
\hline Number of patients followed & $112(81.7)$ & $108(76.0)$ & $1.41[0.78,2.51] ; 0.24$ \\
\hline Number of patients withdrawn & $25(18.3)$ & $34(24.0)$ & $0.70[0.39,1.26] ; 0.24$ \\
\hline Transferred out & $5(3.7)$ & $6(4.2)$ & $0.85[0.25,2.88] ; 0.80$ \\
\hline Deceased & $1(0.7)$ & $4(2.8)$ & $0.25[0.02,2.29] ; 0.18$ \\
\hline Lost to follow-up & 19 (13.9) & $24(17.0)$ & $0.79[0.41,1.52] ; 0.48$ \\
\hline \multicolumn{4}{|l|}{ Punctuality to appointment dates } \\
\hline Early and Prompt & $69(50.4)$ & $70(49.3)$ & $1.04[0.65,1.66] ; 0.85$ \\
\hline \multirow[t]{2}{*}{ Late } & $44(32.1)$ & $38(26.8)$ & $1.29[0.77,2.17] ; 0.32$ \\
\hline & $\begin{array}{l}\text { Mean (SD) / } \\
\text { (Min, Max) }\end{array}$ & & \\
\hline Adherence to prescription drugs (\%, VAS) & $\begin{array}{l}98.9(5.8) / \\
(50,100)\end{array}$ & $\begin{array}{l}99.2(3.8) / \\
(70,100)\end{array}$ & $-0.3[-1.5,1.1] ; 0.73$ \\
\hline \multicolumn{4}{|l|}{ At 6 monthss } \\
\hline \multicolumn{4}{|l|}{ Attendance to appointments } \\
\hline Number of patients followed & $88(64.2)$ & $90(63.4)$ & $1.03[0.63,1.69] ; 0.88$ \\
\hline Number of patients withdrawn & $49(35,8)$ & $52(36.6)$ & $0.96[0.59,1.57] ; 0.88$ \\
\hline Transferred out & $5(3.6)$ & $6(4.2)$ & $0.85[0.25,2.88] ; 0.80$ \\
\hline Deceased & $2(1.5)$ & $6(4.2)$ & $0.33[0.06,1.69] ; 0.16$ \\
\hline Lost to follow-up & $42(30.7)$ & $40(28.2)$ & $1.12[0.67,1.88] ; 0.64$ \\
\hline \multicolumn{4}{|l|}{ Punctuality to appointment dates } \\
\hline Early and Prompt & $65(47.4)$ & $69(48,6)$ & $0.95[0.59,1.52] ; 0.84$ \\
\hline \multirow[t]{2}{*}{ Late } & $23(16.8)$ & $21(14.8)$ & $1.16[0.61,2.21] ; 0.64$ \\
\hline & $\begin{array}{l}\text { Mean (SD) / } \\
\text { (Min, Max) }\end{array}$ & $\begin{array}{l}\text { Mean (SD) / } \\
\text { (Min, Max) }\end{array}$ & $\mathrm{MD}[95 \% \mathrm{Cl}] ; p$ \\
\hline Adherence to prescription drugs (\%, VAS) & $\begin{array}{l}99.7(1.8) / \\
(80,100)\end{array}$ & $\begin{array}{l}99.5(1.7) / \\
(90,100)\end{array}$ & $0.2[-0.4,0.7] ; 0.53$ \\
\hline
\end{tabular}

DOT directly observed treatment, SMS short message service, OR odds ratio, $\mathrm{Cl}$ confidence interval, Early at least 5 days before, Normal between 4 days before and 4 days after, Late starting from 5 days after, SD standard deviation, MD mean difference, VAS visual analog scale 
Table 4 Sociodemographic characteristics of withdrawn participants (transferred and lost to follow-up) at 6 months in intervention group versus control group

\begin{tabular}{|c|c|c|c|}
\hline Variables & $\begin{array}{l}\text { Intervention group } \\
(\mathrm{DOT}+\mathrm{SMS}) n=47\end{array}$ & $\begin{array}{l}\text { Control group } \\
(\mathrm{DOT}) \mathrm{n}=46\end{array}$ & $p$ \\
\hline \multicolumn{4}{|l|}{ Gender: n (\%) } \\
\hline Male & $33(70.2)$ & $26(56.5)$ & 0.17 \\
\hline \multicolumn{4}{|l|}{ Age (years): n (\%) } \\
\hline $18-25$ & $10(21.3)$ & $8(17.4)$ & \multirow[t]{4}{*}{0.13} \\
\hline $26-40$ & $28(59.6)$ & $26(56.5)$ & \\
\hline $41-55$ & $9(19.1)$ & $7(15.2)$ & \\
\hline $56-80$ & $0(0.0)$ & $5(10.9)$ & \\
\hline \multicolumn{4}{|l|}{ Level of Education: n (\%) } \\
\hline None & $3(6.4)$ & $1(2.2)$ & \multirow[t]{4}{*}{0.65} \\
\hline Nusery/primary & $16(34)$ & $16(34.8)$ & \\
\hline Secondary & $23(48.9)$ & $21(45.7)$ & \\
\hline Tertiary & $5(10.6)$ & $8(17.4)$ & \\
\hline \multicolumn{4}{|l|}{ Marital Status: n (\%) } \\
\hline Single & $32(68.1)$ & $28(60.9)$ & \multirow[t]{4}{*}{0.62} \\
\hline Married & $12(25.5)$ & $14(30.4)$ & \\
\hline Cohabitation & $2(4.3)$ & $1(2.2)$ & \\
\hline Widower & $1(2.1)$ & $3(6.5)$ & \\
\hline \multicolumn{4}{|l|}{ Social Category: n (\%) } \\
\hline Student & $5(10.6)$ & $6(13.0)$ & \multirow[t]{5}{*}{0.54} \\
\hline Working in public sector & $1(2.1)$ & $3(6.5)$ & \\
\hline Working in formal private sector & $9(19.1)$ & $6(13.0)$ & \\
\hline Working in informal private sector & $15(31.9)$ & $10(21.7)$ & \\
\hline No work & $17(36.2)$ & $21(45.7)$ & \\
\hline \multicolumn{4}{|l|}{ Monthly income (XAF): n (\%) } \\
\hline$<50,000$ & $18(38.3)$ & $10(21.7)$ & \multirow[t]{4}{*}{0.21} \\
\hline $50,000-149,000$ & $5(10.6)$ & $8(17.4)$ & \\
\hline$>149,000$ & $1(2.1)$ & $0(0.0)$ & \\
\hline Not reported (missing) & $23(48.9)$ & $28(60.9)$ & \\
\hline \multicolumn{4}{|l|}{ HIV Status: n (\%) } \\
\hline Negative & $32(68.1)$ & $31(67.4)$ & \multirow[t]{3}{*}{0.03} \\
\hline Positive & $11(23.4)$ & $4(8.7)$ & \\
\hline Unknown & $4(8.5)$ & $11(23.9)$ & \\
\hline Patient on ART (yes): n (\%) & $2(4.3)$ & $3(6.5)$ & 0.62 \\
\hline
\end{tabular}

DOT directly observed treatment, SMS short message service, 1 US Dollar 599 XAF (F CFA, currency used in Cameroon), HIV human immunodeficiency virus

Here below, we discuss some lessons learned during this study and propose avenues that may improve the effectiveness of a mHealth intervention in general (and by SMS). This is so in particular to sustain the existing DOT, reduced in reality from "daily" to "weekly" or even fewer directly observed strategies. These suggestions are an addition to this study [19] and highlights steps, processes and considerations to take into account in order to develop an SMS-based intervention for promoting adherence to TB treatment.
Further avenues and suggestions

Training of health professionals to improve patient education

The implementation of a mHealth intervention to support DOT needs to train health professionals to better understand challenges like patient education in order to enable them to manage their own treatment course [40, 41]. Principles and concepts underlying effective patient education require the health staff to open a dialogue where the patient is given space and time to become aware about her/ 
Table 5 Sociodemographic characteristics of withdrawn participants (transferred and lost to follow-up) versus all followed participants at 6 months

\begin{tabular}{|c|c|c|c|}
\hline Variables & $\begin{array}{l}\text { Withdrawn at } 6 \text { th month } \\
\text { (Transferred out }+ \text { lost to follow-up) } n=93\end{array}$ & $\begin{array}{l}\text { Present or deceased at 6th month } \\
n=186\end{array}$ & $p$ \\
\hline \multicolumn{4}{|l|}{ Gender: n (\%) } \\
\hline Female & $34(36.6)$ & $80(43.0)$ & \multirow[t]{2}{*}{0.30} \\
\hline Male & $59(63.4)$ & $106(57.0)$ & \\
\hline \multicolumn{4}{|l|}{ Age (years): n (\%) } \\
\hline $18-25$ & $18(19.4)$ & $38(20.4)$ & \multirow[t]{4}{*}{0.99} \\
\hline $26-40$ & $54(58.1)$ & $109(58.6)$ & \\
\hline $41-55$ & $16(17.2)$ & $30(16.1)$ & \\
\hline $56-80$ & $5(5.4)$ & $9(4.8)$ & \\
\hline \multicolumn{4}{|l|}{ Level of education: n (\%) } \\
\hline None & $4(4.3)$ & $7(3.8)$ & \multirow[t]{4}{*}{0.09} \\
\hline Nusery/primary & $32(34.4)$ & $40(21.5)$ & \\
\hline Secondary & $44(47.3)$ & $99(53.2)$ & \\
\hline Tertiary & $13(14.0)$ & $40(21.5)$ & \\
\hline \multicolumn{4}{|l|}{ Marital status: n (\%) } \\
\hline Single & $60(64.5)$ & $117(62.9)$ & \multirow[t]{5}{*}{0.2} \\
\hline Married & $26(28.0)$ & $51(27.4)$ & \\
\hline Cohabitation & $3(3.2)$ & $15(8.1)$ & \\
\hline Widower & $4(4.3)$ & $2(1.1)$ & \\
\hline Divorced & $0(0.0)$ & $1(0.5)$ & \\
\hline \multicolumn{4}{|l|}{ Social category: n (\%) } \\
\hline Student & $11(11.8)$ & $35(18.8)$ & \multirow[t]{5}{*}{0.17} \\
\hline Working in public sector & $4(4.3)$ & $17(9.1)$ & \\
\hline Working in formal private sector & $15(16.1)$ & $20(10.8)$ & \\
\hline Working in informal private sector & $25(26.9)$ & $53(28.5)$ & \\
\hline No work & $38(40.9)$ & $61(32.8)$ & \\
\hline \multicolumn{4}{|l|}{ Monthly income (XAF/ US Dollars): n (\%) } \\
\hline$<50,000$ & $28(30.1)$ & $43(23.1)$ & \multirow[t]{4}{*}{0.36} \\
\hline $50,000-149,000$ & $13(14.0)$ & $32(17.2)$ & \\
\hline$>149,000$ & $1(1.1)$ & $7(3.8)$ & \\
\hline Not reported & $51(54.8)$ & $104(55.9)$ & \\
\hline \multicolumn{4}{|l|}{ HIV status: n (\%) } \\
\hline Negative & $63(67.8)$ & $120(64.5)$ & \multirow[t]{3}{*}{0.40} \\
\hline Positive & $15(16.1)$ & $24(12.9)$ & \\
\hline Unknown & $15(16.1)$ & $42(22.6)$ & \\
\hline
\end{tabular}

Step by step binary logistic regression was done for all variables $(p>0.05)$

his preferences, her/his constraints, and to express these to the care-giver.

Customized messages and management of the patient profile Another point of the m-health intervention is to explore customized motivational messages in relation to the patient's profile at the beginning, with a special attention towards the end of the treatment where patients are almost free to free of symptoms. The motivational messages would target some features of the compliance with treatment: to invite, to motivate, to encourage and to recall appointment date, or even to reward accomplished steps of the cure. Furthermore, the SMS contents should take into account the information-motivation-behavioral (IMB) skills model including contextual elements such as culture, language, beliefs, and factors influencing access to health care $[19,42,43]$. 
In our setting, withdrawn population is mainly composed of people who are: males; aged between 26 and 40 years; with nursery, primary or secondary level of education; single; not working or working in the informal private sector, and with no or low monthly income. Although the association is not statistically significant, the implementation of an effective information system using the potential of information technology as recommended by WHO [44] for collecting profile and treatment data - could be effective for improving compliance.

\section{Interactive mHealth intervention}

Our study corroborated the results of a study exploring the acceptance and perception of SMS uses to improve TB treatment compliance [22]. However, sending only SMS denotes a "one-way" communication which is contradictory to effective patient education. We therefore suggest to develop an interactive m-health combining SMS reminders, sent to patients by the healthcare staff, with the possibility given to patients to submit their own questions and concerns back to the healthcare professionals. In addition, phone-calls completing SMS messages could also reinforce therapeutic relationship enabling patients to respond treatment requirements as for example to come back for final appointment with smear test at 6th month. As our results suggest, the mHealth interventions should be especially targeted at maintaining patient compliance between months five and six, where around $50 \%$ of patient's withdrawn are registered. We postulate that it is relevant to emphasise and increase interactions with patients during this period. The challenge also lies in the health staff, which should be able to deliver a high quality and efficient patient-centered relationship.

Beyond the motivational messages, mHealth-based interventions which would try to reproduce the DOT principle, namely the observation of patient taking his medication, could be an alternative. As the coverage of smartphones expands, one could imagine that patients start to send footages of either themselves taking their medications, or the packaging of drugs on a daily basis ("picture-observed drug intake"). Alternatively, we can explore mHealth approaches that rely on social incentives, such as cooperation and competition, to motivate users in achieving health goals [45].

\section{Adaptation of health policy with concern to financing $T B$ care}

The monitoring of the cure proportion is a crucial indicator of any TB care program. Therefore, patients should be encouraged for the final clinical and laboratory exams at 6 months. However, our data with important drop-out rate after 5 months of treatment indicate that the actual procedures - requiring out-of-the-pocket payment by the patient to afford this final exam - could represent a major obstacle to this. A national TB control program should include at least this final exam, as the Global Fund [46] provides TB drugs free of charge for patients. The fact that socially underprivileged people are more vulnerable to become infected with TB [47] underlines the relevance to adapt health policy based on real costs of TB care. Taking into account the social context of patients will enable to optimise patient retention, enhance DOTS performances and reinforce the reliability of national epidemiological surveillance.

\section{Conclusions}

This study suggests that SMS reminders do not statistically significantly increase proportions of the treatment success at 5 months and the cure at 6 months. However, the low proportion of patients cured at 6 months may be an underestimation due to a high dropout rate between the fifth and the sixth month of treatment. We hope that lessons learned from this study and outlined above will help to reduce the dropout rate and increase the effectiveness of future mHealth intervention studies about management of tuberculosis patients.

\section{Abbreviations \\ 2RHEZ/4RH: 2 months of Rifampicin, Isoniazid, Ethambutol, Pyrazinamide and 4 months of Rifampicin and Isoniazid; ART: Anti-retroviral therapy; ARV: Antiretroviral; BCG: Bacille Calmette Guerin; CONSORT: CONsolidated Standards of Reporting Trials; DOTS: Directly observed treatment short- course; HIV: Human immunodeficiency virus; ISPM: Institute of Social and Preventive Medicine; ITT: Intention to treat; KB: Koch Bacillus; Max: Maximum; MD: Mean difference; mHealth: Mobile Health; Min: Minimum; OR: Odds ratio; PLWHIV: Persons living with HIV; PNLT: National Program for the fight against tuberculosis; SD: Standard deviation; SMS: Short message service; SS + PTB: Sputum Smear-positive Pulmonary Tuberculosis; TB: Tuberculosis; TDC: Treatment and diagnostic centres; VAS: Visual analog scale; WHO: World Health Organisation}

\section{Acknowledgments}

This work was supported by the National Tuberculosis Control Program (Cameroon) and the University of Geneva.

\section{Funding}

This study received 4000 euros from the University of Geneva for purchasing SMS credits and external monitoring. The Faculty of Medicine and Biomedical Sciences of the University of Yaoundé I made available a principal investigator to carry out the study. The National Tuberculosis Control Program of Cameroon provided a research assistant who was responsible for weekly collection of data and daily sending of SMS.

\section{Availability of data and materials}

The dataset used and analysed during the current study is available from the corresponding author on reasonable request.

\section{Authors' contributions}

GB: was involved in the conception, the implementation, the writing and the editing of this study. BS: was involved in the conception, the writing and the revising of this study. NE: was involved in the data analysis, the revising and the editing of study. JLA: was involved in the implementation and the revising of this study. AG: was involved in the conception and the revising of this study. GB, BS has translated the final French version of the paper in English. GB, BS, NE and AG corrected the English version and approved it. All authors have read and approved the final version of the manuscript. 


\section{Authors' information}

GB is a Medical Doctor, with a Master of Advanced Studies in Medical Informatics and a Master of Advanced Studies in Public Health, Research and Teaching Assistant at the Faculty of Medicine and Biomedical Sciences (University of Yaoundé I).

BS: Medical Doctor, MPH, Coordinator of Master in Global Health, Institute of Global Health, University of Geneva.

NE: Medical Doctor, MSc Epidemiology, Institute of Global Health, University of Geneva.

JLA: Medical Doctor, MPH, Head of Cameroon National Program for the fight against tuberculosis.

AG: Medical Doctor, Professor, Head of Department of Medical Informatics and Radiology, University of Geneva.

\section{Ethics approval and consent to participate}

This study was carried out according to ethical principles of the Helsinki declaration [48] and to local recommendations on medical research. It obtained Ethics clearance from the Cameroon National Ethics Committee $\left(n^{\circ}\right.$ 072/CNE/SE/2012) and administrative authorisation of the Ministry of Public Health of Cameroon ( $n^{\circ}$ D301312/AAR/MINSANTE/SESP/SG/DROS/CRC/CEAI). All recruited participants were required to have signed a consent form after receiving key information about the study: objectives, duration, data collection process, expected results and benefits, voluntary character of their participation and the possibility to withdraw at any moment, confidentiality of use of data and of results obtained.

\section{Competing interests}

The author(s) declare that they have no competing interests.

\section{Publisher's Note}

Springer Nature remains neutral with regard to jurisdictional claims in published maps and institutional affiliations.

\section{Author details}

'Faculty of Medicine and Biomedical Sciences, University of Yaoundé I, P.O Box: 1364, Yaoundé, Cameroon. ${ }^{2}$ Geneva Tumour Registry, Institute of Global Health, Faculty of Medicine, University of Geneva, Geneva, Switzerland. ${ }^{3}$ National Tuberculosis Control Program, Ministry of Public Health, Yaoundé, Cameroon. ${ }^{4}$ Department of Radiology and Medical Informatics, Faculty of Medicine, University of Geneva, Geneva, Switzerland.

\section{Received: 14 July 2017 Accepted: 24 April 2018}

Published online: 02 May 2018

\section{References}

1. de la Vía E, Baron R, Molins E, Arriero JM. Tuberculosis. Arch Bronconeumol. 2011;47 Suppl 8:10-4.

2. Rieder HL. The global importance of tuberculosis. Ther Umsch. 2011;68: 359-64.

3. Programme National de Lutte contre la Tuberculose au Cameroun. Guide technique pour les personnels de santé. 2011.

4. World Health Organization (WHO). Tuberculosis: the five elements of DOTS. http://www.who.int/tb/dots/whatisdots/en/index4.html. Accessed May 2018.

5. Organisation Mondiale de la Santé (OMS). Plan mondial halte à la tuberculose 2006-2015: agir pour la vie, vers un monde sans tuberculose. (WHO/HTM/STB/2006.35). 2006. Genève, Organisation Mondiale de la Santé.

6. World Health Organiszation. Plan mondial halte à la tuberculose 2011-2015. http://www.stoptb.org/assets/documents/global/plan/stopTB2011_ overview_FR.pdf. Accessed May 2018.

7. World Health Organization. WHO End TB Strategy. http://www.who.int/tb/ post2015_strategy/en/. Accessed May 2018.

8. World Health Organization. An Expanded DOTS Framework for Effective Tuberculosis Control. Stop TB Communicable Diseases, Geneva 2002. http:// apps.who.int/iris/bitstream/10665/67232/1/WHO_CDS_TB_2002.297.pdf. Accessed May 2018.

9. Haynes RB, Ackloo E, Sahota N, McDonald HP, Yao X. Interventions for enhancing medication adherence. Cochrane Database Syst Rev. 2008;16(2): CD000011.

10. Ongugo K, Hall J, Attia J. Implementing tuberculosis control in Papua New Guinea: a clash of culture and science? J Community Health. 2011; 36:423-30.
11. Volmink J, Garner P. Directly observed therapy for treating tuberculosis. Cochrane Database Syst Rev. 2007;17(4):CD003343.

12. M'Imunya JM, Kredo T, Volmink J. Patient education and counselling for promoting adherence to treatment for tuberculosis (review). Cochrane Library. 2012;16(5):CD006591.

13. Ormerod LP, Prescott RJ. Inter-relations between relapses, drug regimens and compliance with treatment in tuberculosis. Respir Med. 1991;85:239-42.

14. Weis SE, Slocum PC, Blais FX, King B, Nunn M, Matney GB, et al. The effect of directly observed therapy on the rates of drug resistance and relapse in tuberculosis. N Engl J Med. 1994;330:1179-84.

15. Mitchison DA. How drug resistance emerges as a result of poor compliance during short course chemotherapy for tuberculosis. Int J Tuberc Lung Dis. 1998;2:10-5.

16. Goble M, Iseman MD, Madsen LA, Waite D, Ackerson L, Horsburgh CR Jr. Treatment of 171 patients with pulmonary tuberculosis resistant to isoniazid and rifampin. N Engl J Med. 1993;328:527-32.

17. World Health Organization. Health Statistics of Cameroon. http://www.who. int/gho/countries/cmr.pdf. Accessed May 2018.

18. Lei X, Liu Q, Wang H, Tang X, Li L, Wang Y. Is the short messaging service feasible to improve adherence to tuberculosis care? A cross-sectional study. Trans R Soc Trop Med Hyg. 2013;107:666-8.

19. Iribarren SJ, Beck SL, Pearce PF, Chirico C, Etchevarria M, Rubinstein F. mHealth intervention development to support patients with active tuberculosis. J Mob Technol Med. 2014;3:16-27.

20. Elangovan R, Arulchelvan S. A study on the role of mobile phone communication in tuberculosis DOTS treatment. Indian J Community Med. 2013;38:229-33.

21. Mohammed S, Siddiqi O, Ali O, Habib A, Haqqi F, Kausar M, et al. User engagement with and attitudes towards an interactive SMS reminder system for patients with tuberculosis. J Telemed Telecare. 2012;18:404-8.

22. Albino S, Tabb KM, Requena D, Egoavil M, Pineros-Leano MF, Zunt JR, et al. Perceptions and acceptability of short message services technology to improve treatment adherence amongst tuberculosis patients in Peru: a focus group study. PLoS One. 2014;9:e95770.

23. Iribarren S, Beck S, Pearce PF, Chirico C, Etchevarria M, Cardinale D, et al. TextTB: a mixed method pilot study evaluating acceptance, feasibility, and exploring initial efficacy of a text messaging intervention to support TB treatment adherence. Tuberc Res Treat. 2013;2013:349394.

24. Person AK, Blain ML, Jiang H, Rasmussen PW, Stout JE. Text messaging for enhancement of testing and treatment for tuberculosis, human immunodeficiency virus, and syphilis: a survey of attitudes toward cellular phones and healthcare. Telemed J E Health. 2011;17:189-95.

25. Chen TC, Lin WR, Lu PL, Lin CY, Lin SH, Lin CJ, et al. Computer laboratory notification system via short message service to reduce health care delays in management of tuberculosis in Taiwan. Am J Infect Control. 2011;39:426-30.

26. Zimic M, Coronel J, Gilman RH, Luna CG, Curioso WH, Moore DA. Can the power of mobile phones be used to improve tuberculosis diagnosis in developing countries? Trans R Soc Trop Med Hyg. 2009;103:638-40.

27. Hüsler J. Evaluation of the on cue compliance service pilot. Testing the use of SMS reminders in the treatment of tuberculosis in cape town, South Africa. Technology associate, bridges.Org. 2005. City of Cape Town Health Directorate and the InternationalDevelopment Research Council (IDRC).

28. Liu Q, Abba K, Alejandria MM, Sinclair D, Balanag VM, Lansang MA. Reminder systems to improve patient adherence to tuberculosis clinic appointments for diagnosis and treatment. Cochrane Database Syst Rev. 2014;11:CD006594.

29. Nglazi MD, Bekker LG, Wood R, Hussey GD, Wiysonge CS. Mobile phone text messaging for promoting adherence to anti-tuberculosis treatment: a systematic review. BMC Infect Dis. 2013;13:566.

30. Kunawararak $P$, Pongpanich $S$, Chantawong $S$, Pokaew $P$, Traisathit $P$, Srithanaviboonchai $\mathrm{K}$, et al. Tuberculosis treatment with mobile-phone medication reminders in northern Thailand. Southeast Asian J Trop Med Public Health. 2011:42:1444-51.

31. Bediang G, Stoll B, Elia N, Abena JL, Nolna D, Chastonay P, et al. SMS reminders to improve the tuberculosis cure rate in developing countries (TB-SMS Cameroon): a protocol of a randomised control study. Trials. 2014; 15:35.

32. Schulz KF, Altman DG, Moher D. CONSORT 2010 statement: updated guidelines for reporting parallel group randomised trials. Int J Surg. 2011(9): $672-7$. 
33. OPen Epi (online software). http://www.openepi.com/Menu/OE_Menu.htm Accessed May 2018.

34. Ecommerce media home. https://www.facebook.com/ecmhsarl/. Accessed May 2018.

35. Genexpert. https://www.tbfacts.org/xpert-tb-test/. Accessed May 2018.

36. Organisation Mondialde de la Santé (OMS) Obstacles à la réalisation des objectifs de la lutte antituberculeuse: tuberculoses multirésistantes. http:// www.who.int/bulletin/volumes/85/5/06-035345-ab/fr/. Accessed May 2018,

37. Sandhu GK. Tubercuslosis: current situation, challenges and overview of its control programs in India. J Glob Infect Dis. 2011;3:143-50.

38. Ibrahim KM, Khan S, Laaser U. Tuberculosis control: current status, challenges and barriers ahead in 22 high endemic countries. J Ayub Med Coll Abbottabad. 2002;14:11-5.

39. Verver S, Warren RM, Beyers N, Richardson M, van der Spuy GD, Borgdorff MW, et al. Rate of reinfection tuberculosis after successful treatment is higher than rate of new tuberculosis. Am J Respir Crit Care Med. 2005;171: $1430-5$.

40. Lewis CP, Newell JN. Improving tuberculosis care in low income countries a qualitative study of patients' understanding of "patient support" in Nepal. BMC Public Health. 2009;9:190.

41. Macq J, Torfoss T, Getahun H. Patient empowerment in tuberculosis control: reflecting on past documented experiences. Tropical Med Int Health. 2007: 12:873-85.

42. Fisher JD, Fisher WA, Amico KR, Harman JJ. An information-motivationbehavioral skills model of adherence to antiretroviral therapy. Health Psychol. 2006:25:462-73.

43. Munro S, Lewin S, Swart T, Volmink J. A review of health behaviour theories: how useful are these for developing interventions to promote long-term medication adherence for TB and HIV/AIDS? BMC Public Health. 2007;7:104.

44. World Health Organization, Management Sciences for Health, KNCV

Tuberculosis Foundation: Electronic recording and reporting for tuberculosis care and control. Who/HTM/TB/2011 222012.

45. Al Ayubi SU, Parmanto B, Branch R, Ding D. A persuasive and socia mHealth application for physical activity: a usability and feasibility study. JMIR Mhealth Uhealth. 2014;2:e25.

46. The Global Fund. http://www.theglobalfund.org/en/. Accessed May 2018.

47. Basta PC, Marques M, Oliveira RL, Cunha EA, Resendes AP, Souza-Santos R. Social inequalities and tuberculosis: an analysis by race/color in Mato Grosso do Sul, Brazil. Rev Saude Publica. 2013;47:854-64.

48. World Medical Association Declaration of Helsinki. Ethical principles for medical research involving human subjects. Nurs Ethics. 2002;9:105-9.

\section{Ready to submit your research? Choose BMC and benefit from:}

- fast, convenient online submission

- thorough peer review by experienced researchers in your field

- rapid publication on acceptance

- support for research data, including large and complex data types

- gold Open Access which fosters wider collaboration and increased citations

- maximum visibility for your research: over $100 \mathrm{M}$ website views per year

At BMC, research is always in progress.

Learn more biomedcentral.com/submissions 